\title{
Should We Cease to Perform Salvage Hysterectomy After Chemoradiation and Brachytherapy in Locally Advanced Cervical Cancer?
}

\author{
MARIE GOSSET ${ }^{1}$, CYRUS CHARGARI $^{2,3}$, ERICA BENTIVEGNA $^{1}$, ALEXANDRA LEARY $^{4}$, \\ CATHERINE GENESTIE ${ }^{5}$, AMANDINE MAULARD ${ }^{1}$, PHILIPPE MORICE $^{1,3}$ and SEBASTIEN GOUY ${ }^{1}$ \\ ${ }^{1}$ Department of Surgery, Gustave Roussy, Villejuif Cedex, France; \\ ${ }^{2}$ Department of Radiotherapy, Gustave Roussy, Villejuif Cedex, France; \\ ${ }^{3}$ Paris Sud University, Kremlin Bicêtre, France; \\ ${ }^{4}$ Department of Oncology, Gustave Roussy, Villejuif Cedex, France; \\ ${ }^{5}$ Department of Biology and Pathology, Gustave Roussy, Villejuif Cedex, France
}

\begin{abstract}
Background/Aim: We evaluated patients undergoing salvage hysterectomy after brachytherapy (BT) following concomitant chemoradiation (CRT) for locally advanced cervical cancers (LACC), when residual disease was suspected. Patients and Methods: From 2004 to 2013, 29 patients had a radical hysterectomy at the Gustave Roussy for suspicion of clinical and/or radiological residual disease. Outcomes, morbidities and the accuracy of the evaluation of response to CRT and BT were evaluated. Results: The rate of complications grade>IIIa was $24 \%$, with no difference between the 14 patients with histological residual disease and the 15 with a complete response. Magnetic resonance imaging (MRI) and positron emission tomography-computed tomography (PET-CT) revealed a sensitivity of $92 \%$ and $100 \%$, but a poor specificity of less than 40\%. Three recurrences occurred in patients with residual disease (brain, rectosigmoid colon, peritoneum and lung). Conclusion: The clinical examination, MRI and PET-CT are suboptimal for diagnosing residual disease after CRT and BT. The morbidity of adjuvant hysterectomy is high and does not prevent recurrences.
\end{abstract}

Brachytherapy (BT) following concomitant chemoradiation (CRT) is the standard treatment for locally advanced cervical cancer (LACC: stage $\geq \mathrm{IB} 2$ according to the Fédération Internationale de Gynécologie et d'Obstétrique [FIGO]

This article is freely accessible online.

Correspondence to: Marie Gosset, MD, Department of Surgery, Gustave Roussy, 114, rue Edouard Vaillant, 94805, Villejuif Cedex, France. Tel: +33 672202948, e-mail: marie.gosset@outlook.com

Key Words: Locally advanced cervical cancer, chemoradiation therapy, brachytherapy salvage hysterectomy, morbidity. classification). Due to concomitant CRT and 3D image-guided adaptive BT, dose escalations are possible and yield excellent local control while shielding organs at risk $(1,2)$. Adjuvant hysterectomy has no impact on patients with a complete response after BT following CRT (3-8), but it continues to fuel debate when residual disease is suspected (8). The evaluation of residual cervical disease is uncertain. Magnetic resonance imaging (MRI) is not an optimal technique for predicting response to initial treatment because of the risk of falsepositives $(9,10)$. Besides the difficulties encountered when evaluating response to CRT and BT, salvage hysterectomy causes a high rate of postoperative complications $(\sim 25 \%)(11$, 12). The aims of this study were to evaluate outcomes and morbidities in patients who had undergone salvage hysterectomy for suspicion of residual LACC after CRT followed by BT. The accuracy of the clinical and radiological evaluation of response to CRT and BT was also evaluated.

\section{Patients and Methods}

All experiments were performed retrospectively and in accordance with the French Bioethics Law 2004-800, the French National Institute of Cancer (INCa) Ethics Charter and after approval by the Gustave Roussy review board and ethics committee. In the French legal context, our institutional review board waived the need for written informed consent from the participants. Data were analyzed anonymously. We retrospectively identified patients treated with BT following concomitant CRT from 2004 to 2013 for locally advanced cervical cancer (LACC) at Gustave Roussy. Patients referred from other centers after CRT for BT and completion surgery were also screened. Squamous cell carcinomas and adenocarcinomas were included, whereas small cell and clear cell carcinomas were excluded. Inclusions were limited to stages exceeding IB2 according to the FIGO classification. After the initial treatment, a clinical and radiological evaluation had been performed. Only patients who had undergone a salvage hysterectomy for clinical and/or radiological suspicion of residual disease were included. 
Table I. Dindo classification (19).

Dindo classification - surgical complication

Grade I Any deviation from the normal postoperative course without the need for pharmacological treatment or surgical, endoscopic, and radiological interventions

Allowed therapeutic regimens are: drugs as antiemetics, antipyretics, analgesics, diuretics, electrolytes, and physiotherapy.

This grade also includes wound infections opened at the bedside

Grade II Requiring pharmacological treatment with drugs other than such allowed for grade I complications. Blood transfusions and total parenteral nutrition are also included

Grade III Requiring surgical, endoscopic or radiological intervention

III a Intervention not under general anesthesia

III $b \quad$ Intervention under general anesthesia

Grade IV Life-threatening complication (including CNS complications)* requiring IC/ICU management

IV a Single-organ dysfunction (including dialysis)

IV b Multiorgan dysfunction

Grade V Death of a patient

Initial treatments. All patients had received pelvic conformal external beam radiotherapy (EBRT) delivering 45-50.4 Gy in 25-28 fractions of 1.8 Gy over 5 weeks (13). Concomitant chemotherapy consisting of cisplatin $\left(40 \mathrm{mg} / \mathrm{m}^{2}\right)$ was systematically administered. Sequential nodal boosts were delivered after completion of BT, based on node dimensions and characteristics on initial MRI/CT, or PET-CT positivity. The aim was to deliver a total dose of 60 Gy to all positive nodes. EBRT was followed by image-guided adaptive BT following the GEC-ESTRO (Groupe Européen de Curiethérapie - European Society for Radiation Oncology) recommendations (14, 15). A personalized vaginal mold was used in nearly all applications (16). The structures of interest were delineated following the GECESTRO recommendations (14). The dosimetry started from a standard prescription of $15 \mathrm{~Gy}$.

Post-treatment evaluation. Patients underwent a clinical evaluation, at least 3 weeks after the end of brachytherapy. In some patients, cytologic and biopsy samplings were obtained. Clinical categorization of the gynecologic examination was retrospectively based on the report of the consultation at the end of treatment. A radiological evaluation of residual disease was also performed in the same week of the clinical examination, with pelvic MRI and/or PET-CT. Sensitivity, specificity, and positive and negative predictive values of each examination were calculated, comparing the result of the examination with the histologic analysis of the salvage hysterectomy specimen.

Para-aortic staging and radical hysterectomy. Hysterectomies were usually scheduled 8-12 weeks after the completion of BT. Before 2007, para-aortic node (PAN) staging was performed at the time of salvage hysterectomy. From 2007 onward, patients with negative MRI and PET-CT scans at the PAN level underwent laparoscopic staging, and the decision to extend the radiotherapy fields was based on the histologic results (17). As the positive predictive value of PET-CT is high, laparoscopic staging was not performed in patients with a positive PAN scan and extended-field radiotherapy was delivered (18).
Outcomes. After hysterectomy, microscopic residual disease was defined as $\leq 1 \mathrm{~cm}$ in width. Patients were followed up every 4 months over 3 years, then every 6 months for 2 years, and yearly thereafter. No specific examination was recommended in addition to the clinical examination. CT scan, MRI and/or PET-CT were only performed depending on symptoms. Local relapses were defined as any relapse in the vaginal cuff, vagina, and parametria. All times and survival were defined from the date of the diagnosis (first biopsy). Morbidity was graded using the Dindo classification (19) (Table I).

\section{Results}

Thirty-one patients with clinical and/or radiological suspicion of residual disease had undergone a salvage hysterectomy. Two patients were excluded, because of the histologic type (small cell carcinoma and neuroendocrine tumor respectively), and 29 patients fulfilled the inclusion criteria. Patient characteristics are summarized in Table II, and are also described according to the type of response after BT following CRT (residual disease or complete response). Data concerning both groups were similar. Median age at cancer diagnosis was 45.8 years. Patients had FIGO clinical stages IB2 $(n=8)$, IIA $(n=2)$, IIB $(n=18)$ and III $(n=1)$. Twenty-two patients had squamous cell carcinoma and 7 patients had adenocarcinoma. Four patients had pelvic lymph node invasion at initial radiological staging. Nine patients had undergone a para-aortic lymphadenectomy for surgical staging and one patient had nodal involvement. The other patients had undergone a paraaortic lymphadenectomy during the salvage hysterectomy. The median duration of CRT followed by BT was 47.4 days and the median interval from BT to the salvage hysterectomy was 76 days. According to Querleu's classification, radical hysterectomy was type A in 19 patients, type B in 5 and type $\mathrm{C}$ in 5. Five patients had undergone a laparoscopy, the others, 
Table II. Patient characteristics.

\begin{tabular}{|c|c|c|c|}
\hline & $\begin{array}{l}\text { Total } \\
\mathrm{n}=29\end{array}$ & $\begin{array}{c}\text { Residual disease } \\
\mathrm{n}=14\end{array}$ & $\begin{array}{l}\text { Complete response } \\
\qquad \mathrm{n}=15\end{array}$ \\
\hline Median age at diagnosis (years, min-max) & $46(30-63)$ & $43(37-60)$ & $46(30-63)$ \\
\hline \multicolumn{4}{|l|}{ FIGO stage } \\
\hline IB2 & 8 & 5 & 3 \\
\hline IIA & 2 & 1 & 1 \\
\hline IIB & 18 & 8 & 10 \\
\hline III & 1 & 0 & 1 \\
\hline \multicolumn{4}{|l|}{ Histology } \\
\hline SCC & 22 & 8 & 14 \\
\hline $\mathrm{ADC}$ & 7 & 6 & 1 \\
\hline Initial mean tumor width $(\mathrm{mm})$ & $50(30-80)$ & $50(40-75)$ & $48(30-80)$ \\
\hline Lymph node invasion at initial staging (MRI, CT) & 4 & 0 & 0 \\
\hline Unilateral pelvic lymph node invasion & 2 & 0 & 2 \\
\hline Bilateral pelvic lymph node invasion & 2 & 1 & 1 \\
\hline Para-aortic lymph node invasion & 0 & 0 & 0 \\
\hline Para-aortic lymphadenectomy for surgical staging & 9 & 6 & 3 \\
\hline Initially positive para-aortic lymph node(s) & $1 *$ & 0 & 1 \\
\hline CRT and BT - median duration: (days min-max) & $47(37-64)$ & $49(37-64)$ & $46(38-52)$ \\
\hline Interval between brachytherapy \& surgery (days) & $76(47-200)$ & $71(47-140)$ & $76(50-200)$ \\
\hline \multicolumn{4}{|l|}{ Salvage hysterectomy: surgical procedure } \\
\hline Laparoscopy & 5 & 2 & 3 \\
\hline Laparotomy & 24 & 12 & 12 \\
\hline \multicolumn{4}{|l|}{ Type of salvage hysterectomy** } \\
\hline Total hysterectomy Type A & 19 & 9 & 10 \\
\hline Extended hysterectomy Type B & 5 & 3 & 2 \\
\hline Extended hysterectomy Type C & 5 & 2 & 3 \\
\hline \multicolumn{4}{|l|}{ Lymphadenectomy during salvage hysterectomy } \\
\hline Pelvic & 1 & 1 & 0 \\
\hline Para-aortic & 19 & 7 & 12 \\
\hline Pelvic and para-aortic & 1 & 1 & 0 \\
\hline \multicolumn{4}{|l|}{ Positive lymph node(s) after salvage surgery } \\
\hline Pelvic lymph node invasion alone & 1 & 1 & 0 \\
\hline Para-aortic lymph node invasion alone & 1 & 1 & 0 \\
\hline Pelvic and para-aortic lymph node invasion & 1 & 1 & 0 \\
\hline Adjuvant chemotherapy* & 2 & 2 & 0 \\
\hline
\end{tabular}

*Macro-metastasis (>5 mm), para-aortic radiotherapy (45 Gy); **Querleu classification: Type A: minimum resection of paracervix, Type B: transection of paracervix at the ureter, Type $\mathrm{C}$ : transection of paracervix at junction with internal iliac vascular system; **1 carboTaxol, 1 CisP Topotecan.

a laparotomy. Fourteen patients had histologically proven residual disease, (microscopic in 5 and macroscopic in 9).

Two patients had undergone a pelvic lymphadenectomy, with nodal involvement in both. Three patients had positive para-aortic lymph nodes, all macro-metastases $(>5 \mathrm{~mm})$. Among these three patients, one had undergone a para-aortic lymphadenectomy for surgical staging and had therefore received para-aortic radiotherapy (45 Gy). The other two patients had undergone a para-aortic lymphadenectomy at the time of the salvage hysterectomy, with no additional radiotherapy. One of these two patients had positive pelvic lymph nodes.

Evaluation after BT following concomitant CRT. The clinical examination, MRI and PET-CT revealed a sensitivity of
$93 \%, 92 \%$ and $100 \%$ respectively. The specificity of each method was $40 \%, 0 \%$ and $33 \%$ respectively.

One case was considered as having achieved a complete response on MRI but the PET-CT scan depicted residual disease, which was confirmed by the histological analysis. Seven patients had a negative cervical biopsy $(n=3)$ or cytology $(n=4)$ but residual disease was confirmed in all of them on MRI and after the histological analysis (Tables III, IV, V, VI).

Postoperative complications. The rate of complications exceeding grade IIIa was $24 \%$, with no difference between the 14 patients with histologically proven residual disease and the 15 patients with a complete response (21\% and $27 \%$ respectively) (Table VII). The types of surgery were similar in the two groups. The most common complications were 
Table III. Evaluation after BT following concomitant CRT (clinical examination).

\begin{tabular}{lccc}
\hline $\begin{array}{l}\text { Clinical examination } \\
(\mathrm{n}=29)\end{array}$ & \multicolumn{2}{c}{ Histological findings } \\
\cline { 2 - 3 } & Residual disease & Complete response & \\
\hline Suspicion of residual disease $(\mathrm{n}=22)$ & 13 & 9 & PPV=93\% \\
No suspicion of residual disease $(\mathrm{n}=7)$ & 1 & Specificity $=40.0 \%$ & NPV=85.7\% \\
\hline
\end{tabular}

Table IV. Evaluation after BT following concomitant CRT (cervical cytology or biopsy).

\begin{tabular}{lccc}
\hline $\begin{array}{l}\text { Cervical cytology or biopsy } \\
(\mathrm{n}=13)\end{array}$ & \multicolumn{2}{c}{ Histological findings } \\
\cline { 2 - 4 } & Residual disease & Complete response \\
\hline Positive $(\mathrm{n}=7)$ & 0 & 7 & - \\
Normal $(\mathrm{n}=6)$ & 0 & 6 & NPV=100\% \\
& Sensitivity=0\% & Specificity $=46.1 \%$ & \\
\hline
\end{tabular}

Table V. Evaluation after BT following concomitant CRT (MRI).

\begin{tabular}{lccc}
\hline $\begin{array}{l}\text { MRI } \\
(\mathrm{n}=26)\end{array}$ & \multicolumn{2}{c}{ Histological findings } \\
\cline { 2 - 3 } & Residual disease & Complete response \\
\hline Suspicion of residual disease $(\mathrm{n}=25)$ & 12 & 13 & PPV=48\% \\
Complete response $(\mathrm{n}=1)$ & 1 & 0 & $\mathrm{NPV}=0 \%$ \\
& Sensitivity=92.3\% & Specificity=0\% \\
\hline
\end{tabular}

Table VI. Evaluation after BT following concomitant CRT (PET CT).

\begin{tabular}{lccc}
\hline $\begin{array}{l}\text { PET CT } \\
(\mathrm{n}=10)\end{array}$ & \multicolumn{2}{c}{ Histological findings } \\
\cline { 2 - 3 } & Residual disease & Complete response \\
\hline Suspicion of residual disease $(\mathrm{n}=8)$ & 4 & 4 & 2 \\
Complete response $(\mathrm{n}=5)$ & 0 & SPV $=50 \%$ & $\mathrm{NPV}=100 \%$ \\
& Sensitivity=100\% & Specificity $=33.3 \%$ & \\
\hline
\end{tabular}

related to lymphorrhea: one patient had undergone puncture of a pelvic abscess, another, CT-guided puncture of a lymphocele causing renal obstruction and one other patient had chylous ascites requiring a laparotomy for surgical lymphostasis. One patient had a ureteral fistula with unilateral renal obstruction that had been treated with a double pigtail stent. Three patients had a rectovaginal fistula, which was associated with a bladder fistula in one of them. A colostomy had been performed in the three cases.

Patients with residual disease. Fourteen patients had histologically proven residual disease, (microscopic in 5 and macroscopic in 9), with lymphovascular space invasion (LVSI) in $50 \%$ of the cases $(n=2$ for microscopic and $n=5$ for macroscopic residual disease). The median tumor size was 19 $\mathrm{mm}$ (range=6-40 mm). Two patients had positive surgical margins. One patient had pelvic lymph node invasion alone (but had not undergone a para-aortic lymphadenectomy), one had para-aortic lymph node invasion alone (but without a pelvic lymphadenectomy) and one had pelvic and para-aortic lymph node invasion. All patients with positive lymph nodes had LVSI.

Post salvage surgery recurrences. Three recurrences had arisen in patients with histologically proven residual disease 
Table VII. Postoperative complications.

\begin{tabular}{|c|c|c|c|c|c|}
\hline & & $\begin{array}{l}\text { Total } \\
\mathrm{n}=29\end{array}$ & $\begin{array}{l}\text { Residual disease } \\
\mathrm{n}=14\end{array}$ & $\begin{array}{l}\text { Complete response } \\
\qquad \mathrm{n}=15\end{array}$ & $\begin{array}{c}\text { OR, p } \\
(95 \% \mathrm{CI})^{*}\end{array}$ \\
\hline \multicolumn{6}{|l|}{ Surgical technique } \\
\hline Laparotomy & & 24 & 12 & 12 & \\
\hline Laparoscopy & & 5 & 2 & 3 & \\
\hline \multicolumn{6}{|l|}{ Type of salvage hysterectomy** } \\
\hline Type A & & 19 & 9 & 10 & \\
\hline Type B & & 5 & 3 & 2 & \\
\hline Type C & & 5 & 2 & 3 & \\
\hline \multirow[t]{2}{*}{ Complications $\geq$ Grade $3 \mathrm{a}$} & & $7(24 \%)$ & $3(21 \%)$ & $4(27 \%)$ & $0.76, p=1(0.1-5.7)$ \\
\hline & Treatment & & & & \\
\hline \multicolumn{6}{|l|}{ Grade 3a complications } \\
\hline Pelvic Abscess & CT-guided puncture & 1 & 0 & 1 & \\
\hline Lymphocele with renal obstruction & $\mathrm{CT}$-guided puncture & 1 & 1 & 0 & \\
\hline \multicolumn{6}{|l|}{ Grade $3 b$ complications } \\
\hline Chylous ascites & Laparotomy & 1 & 1 & 0 & \\
\hline Ureteral fistula with renal obstruction & Double pigtail stents & 1 & 0 & 1 & \\
\hline Rectovaginal fistula & Colostomy & 2 & 0 & 2 & \\
\hline Rectovaginal and bladder fistula & Colostomy & 1 & 1 & 0 & \\
\hline
\end{tabular}

*Fisher's exact test; **Querleu classification: Type A: minimum resection of paracervix, Type B: transection of paracervix at the ureter, Type C: transection of paracervix at junction with internal iliac vascular system.

and LVSI. The details are presented in Table VIII. Two patients had microscopic residual disease and one had macroscopic residual disease. The sites of recurrences were the brain, rectosigmoid colon, the peritoneum (carcinosis) with involved pelvic lymph nodes and lung metastasis.

\section{Discussion}

Only a minority of patients with LACC require completion surgery. Concomitant CRT and 3D image-guided adaptive BT yield excellent local control. In the literature, a complete response is observed in $80-95 \%$ of patients $(20,21)$. During our long study period (10 years), only 32 patients had clinical or radiological suspicion of residual disease after BT following CRT.

In our study, postoperative complications $\geq$ grade 3 occurred frequently $(24 \%)$. The rates were similar in cases of residual disease or complete responses, and the types of surgery, according to the Querleu classification, were similar in both groups. Our complication rate was the same as that observed by Touboul et al. in 140 patients treated for LACC: $25 \%$ of the patients experienced 55 postoperative complications. The risk for complications was higher when residual disease was present ( $p=0.01$ ) (12). In the study reported by Azria et al., salvage hysterectomy was performed in 10 patients with bulky $(>2 \mathrm{~cm})$ residual disease and 4 patients experienced grade 3 complications (5). Thus, the morbidity rate of this procedure remains high even if minimally invasive surgery is performed.
Colombo et al., reported a complication rate of $28.3 \%$ with the laparoscopic approach (22). In our study, only five patients had undergone a laparoscopic approach but our complication rate was similar: $24 \%$ versus $28.3 \%$. Moreover, there was no differences in $\geq$ grade 3 postoperative complications according to the histologic status: $27 \%$ for no histologically proven disease and $21 \%$ for histologically proven disease. Even for patients with histologically proven residual disease, the benefit of salvage hysterectomy seems uncertain. Conversely, the morbidity rate (around 25\%) is certain, even for patients without histologically proven residual disease in whom this surgery did not afford any benefit. The burning question is how can we identify patients who definitely have residual disease in order to proceed with surgery only in these patients and avoid pointless surgery in patients without residual disease. Unfortunately, the accuracy of treatment response evaluation before surgery is poor. PET-CT and the clinical examination revealed the best sensitivity in our series. But the specificity of MRI, PET-CT and the clinical examination never exceeded $50 \%$. This is consistent with the series reported by Vincens et al., concerning 44 patients submitted to a salvage hysterectomy after CRT and BT for stage IB2/II cervical cancer. The sensitivity and specificity of MRI in evaluating residual disease were $80 \%$ and $55 \%$, respectively (10). Estimating the tumor volume after CRT and BT may be difficult because of normal tissue changes surrounding residual tumor. Diffusion-weighted MRI and PET may be promising (23, 24). Lin et al. determined the tumor volume using FDG-PET in a prospective study of 32 patients. They showed that tumor 
Table VIII. Characteristics of patients with a recurrence.

\begin{tabular}{|c|c|c|c|}
\hline & Patient 1 & Patient 2 & Patient 3 \\
\hline Age (years) & 56 & 41 & 56 \\
\hline Histologic type & SCC & Adenocarcinoma & $\mathrm{SCC}$ \\
\hline \multicolumn{4}{|l|}{ FIGO stage } \\
\hline \multirow[t]{2}{*}{ Tumor size $(\mathrm{mm})$} & IIB & IIB & IIB \\
\hline & 40 & 50 & 70 \\
\hline $\begin{array}{l}\text { Para-aortic lymphadenectomy } \\
\text { for surgical staging }\end{array}$ & No & Yes & No \\
\hline \multicolumn{4}{|l|}{ Evaluation after BT following CRT } \\
\hline MRI & Negative & $20 \mathrm{~mm}$ & $30 \mathrm{~mm}$ \\
\hline PET-CT & SUV 4.3 & SUV 6.7 & No \\
\hline \multirow[t]{3}{*}{ Surgical technique } & Laparotomy & Laparotomy & Laparotomy \\
\hline & - Extended hysterectomy Type B & - Extended hysterectomy Type C & - Extended hysterectomy Type C \\
\hline & - Para-aortic lymphadenectomy & - Pelvic lymphadenectomy & - Pelvic and para-aortic lymphadenectomy \\
\hline \multirow[t]{4}{*}{ Residual disease } & Microscopic & Macroscopic & Macroscopic, $28 \mathrm{~mm}$ \\
\hline & $\mathrm{N}-$ & $2 \mathrm{~N}+$ & $\begin{array}{l}6 \mathrm{~N}+\text { para-aortic } \\
3 \mathrm{~N}+\text { pelvic }\end{array}$ \\
\hline & LVSI & LVSI & LVSI \\
\hline & Free margins & Margins $<1 \mathrm{~mm}$ & Free margins \\
\hline Adjuvant chemotherapy & No & No & Cisplatin-Topotecan \\
\hline \multirow[t]{2}{*}{ Postoperative complication } & Grade 3 & Grade 2 & No \\
\hline & $\begin{array}{l}\text { Rectovaginal and bladder fistula, } \\
1.7 \text { months after surgery }\end{array}$ & $\begin{array}{l}\text { Lymphocele with } \\
\text { renal dilatation }\end{array}$ & \\
\hline \multicolumn{4}{|l|}{ Recurrence } \\
\hline Time & 43 months & 9 months & 13 months \\
\hline \multirow{3}{*}{ Site } & Brain metastasis (cerebellum) & Pelvic lymph nodes & Rectosigmoid colon \\
\hline & & Peritoneal carcinosis & \\
\hline & & Lung metastasis & \\
\hline Overall survival & 62 months & 23 months & 24 months \\
\hline Progression-free survival & 50 months & 14 months & 21 months \\
\hline
\end{tabular}

SCC: Squamous cell carcinoma; BT: brachytherapy; CRT: chemoradiation therapy; LVSI: lymphovascular space invasion; SUV: standardized uptake value.

volume shrinkage occurred within 20 days of starting therapy (23). Fanfani et al., evaluated cone biopsies after neoadjuvant concomitant CRT in 74 patients with LACC (25). The authors reported a negative predictive value of $100 \%$ but feasibility was around $75 \%$. Indeed, 15 patients were excluded for "unfeasible cone biopsies". Therefore, when residual disease is suspected, cone biopsies could be an option (if feasible) to avoid surgery if the biopsy results are negative.

In our retrospective series, three recurrences had occurred, all of them in patients with residual disease. There was no difference in the pattern of recurrence (locoregional versus distant) among cases with macroscopic residual disease compared to patients with microscopic residual tumor. Mazeron et al., showed that concomitant CRT followed by 3D image-guided BT yields an excellent locoregional control rate (13). Even in patients with residual disease after concomitant CRT and BT, the efficacy of salvage hysterectomy has not been proven in terms of survival $(8,26)$.

This is a monocentric retrospective study. No survival analysis could be performed and the size of our population was small. Due to the efficiency of CRT followed by BT, residual disease is uncommon in LACC and the high rate of complete responses observed was expected. Yet, our study allowed us to identify major challenges for LACC. The main issue is not completion surgery, but the management of patients with an incomplete response to BT following CRT. One study demonstrated a significant benefit of adjuvant chemotherapy after CRT. Patients with LACC (stages IIB to IV) treated with cisplatin-gemcitabine, both during and after radiotherapy, achieved better progressionfree and overall survival (27). Neoadjuvant chemotherapy before radiotherapy could be an option. A review of 18 trials and 2,074 patients published in 2006 demonstrated that the timing and dose intensity of cisplatin-based neoadjuvant chemotherapy before radiotherapy could exert a prognostic impact. However, the data are heterogeneous and require confirmation (28). Recent studies focused on new systemic strategies that could improve survival for patients with persistent, recurrent, or metastatic cervical cancer. The randomized phase III trial of the Gynecologic Oncology Group (GOG 240) evaluated the effectiveness of bevacizumab and non-platinum combination chemotherapy in patients with recurrent, persistent, or metastatic cervical cancer (29). This trial enrolled 452 patients with LACC who received 
1 of 4 possible combination regimens: cisplatin/paclitaxel; topotecan/paclitaxel; cisplatin/paclitaxel/bevacizumab; or topotecan/paclitaxel/bevacizumab. The results revealed significant improvements in overall survival among patients receiving the antiangiogenic agent (17.0 vs. 13.3 months; $p=0.004)$. Topotecan/paclitaxel was not superior compared to cisplatin/paclitaxel. Based on these data, the FDA recently approved bevacizumab as a component of combination therapy with paclitaxel and either cisplatin or topotecan for the treatment of persistent, recurrent, or metastatic cervical cancer (30). In cases of suspected residual disease, this strategy using adjuvant chemotherapy and bevacizumab should be evaluated in a trial. More recently, the NRG Oncology/GOG Study analyzed the prognostic impact of bevacizumab according to risk categories based on Moore criteria (black race, performance status 1 , pelvic disease, prior cisplatin, and progression-free interval $<365$ days). The authors concluded that the benefit of bevacizumab was greatest in the moderate (2-3 factors) and high-risk (4-5 factors) subgroups (a 5.8-month increase in median OS). However, the survival benefit was small for lowrisk patients (0-1 factor) and toxicity concerns may justify omitting bevacizumab in this case (31).

\section{Conclusion}

The clinical examination, MRI and PET-CT remain suboptimal for diagnosing residual disease after concomitant CRT and BT in LACC. The morbidity caused by adjuvant hysterectomy is high and this surgical procedure does not prevent locoregional or distant recurrences. Based on the literature and our results, the major challenge is not completion surgery. We need to accurately identify patients with residual disease after CRT and BT and determine the best treatment for them.

\section{Conflicts of Interest}

Authors have no conflict of interest to declare and there was no financial support for this study.

\section{Authors' Contributions}

All authors make substantial contributions to conception and design, and/or acquisition of data, and/or analysis and interpretation of data: C.C, A.L. and C.G. collected cases. M.G. completed all data. S.G. and M.G. designed the study and analysed data. S.G., M.G. and P.M. co-wrote the paper. C.C. and A.L. revised the materials and methods. A.M. and E.B. revised critically the article. All Authors and gave final approval of the version to be submitted.

\section{References}

1 Chemoradiotherapy for Cervical Cancer Meta-Analysis C: Reducing uncertainties about the effects of chemoradiotherapy for cervical cancer: A systematic review and meta-analysis of individual patient data from 18 randomized trials. J Clin Oncol
26(35): 5802-5812, 2008. PMID: 2645100. DOI: 10.1200/ JCO.2008.16.4368

2 Guedea F: Perspectives of brachytherapy: Patterns of care, new technologies, and "new biology". Cancer Radiother 18(5-6): 434436, 2014. PMID: 25175344. DOI: 10.1016/j.canrad. 2014.07.143

3 Haie-Meder C, Morice P, Castiglione M and Group EGW: Cervical cancer: Esmo clinical recommendations for diagnosis, treatment and follow-up. Ann Oncol 20: 27-28, 2009. PMID: 19454454. DOI: $10.1093 /$ annonc/mdp119

4 Koh WJ, Greer BE, Abu-Rustum NR, Apte SM, Campos SM, Cho KR, Chu C, Cohn D, Crispens MA, Dorigo O, Eifel PJ, Fisher CM, Frederick P, Gaffney DK, Han E, Huh WK, Lurain JR, 3rd, Mutch D, Fader AN, Remmenga SW, Reynolds RK, Teng N, Tillmanns T, Valea FA, Yashar CM, McMillian NR and Scavone JL: Cervical cancer, version 2.2015. J Natl Compr Canc Netw 13(4): 395-404; quiz 404, 2015. PMID: 25870376.

5 Azria E, Morice P, Haie-Meder C, Thoury A, Pautier P, Lhomme C, Duvillard P and Castaigne D: Results of hysterectomy in patients with bulky residual disease at the end of chemoradiotherapy for stage ib2/ii cervical carcinoma. Ann Surg Oncol 12(4): 332-337, 2005. PMID: 15827678. DOI: 10.1245/ ASO.2005.05.020

6 Houvenaeghel G, Lelievre L, Buttarelli M, Jacquemier J, Carcopino $\mathrm{X}$, Viens $\mathrm{P}$ and Gonzague-Casabianca L: Contribution of surgery in patients with bulky residual disease after chemoradiation for advanced cervical carcinoma. Eur J Surg Oncol 33(4): 498-503, 2007. PMID: 17156969. DOI: 10.1016/j.ejso.2006.10.011

7 Morice P, Rouanet P, Rey A, Romestaing P, Houvenaeghel G, Boulanger JC, Leveque J, Cowen D, Mathevet P, Malhaire JP, Magnin G, Fondrinier E, Berille J and Haie-Meder C: Results of the gyneco 02 study, an fnclcc phase iii trial comparing hysterectomy with no hysterectomy in patients with a (clinical and radiological) complete response after chemoradiation therapy for stage ib2 or ii cervical cancer. Oncologist 17(1): 64-71, 2012. PMID: 3267825. DOI: 10.1634/theoncologist.2011-0276

8 Keys HM, Bundy BN, Stehman FB, Okagaki T, Gallup DG, Burnett AF, Rotman MZ, Fowler WC Jr. and Gynecologic Oncology G: Radiation therapy with and without extrafascial hysterectomy for bulky stage ib cervical carcinoma: A randomized trial of the gynecologic oncology group. Gynecol Oncol 89(3): 343-353, 2003. PMID: 12798694.

9 Nam H, Park W, Huh SJ, Bae DS, Kim BG, Lee JH, Lee JW, Lim DH, Han Y, Park HC and Ahn YC: The prognostic significance of tumor volume regression during radiotherapy and concurrent chemoradiotherapy for cervical cancer using MRI. Gynecol Oncol 107(2): 320-325, 2007. PMID: 17675222. DOI: 10.1016/j.ygyno.2007.06.022

10 Vincens E, Balleyguier C, Rey A, Uzan C, Zareski E, Gouy S, Pautier P, Duvillard P, Haie-Meder C and Morice P: Accuracy of magnetic resonance imaging in predicting residual disease in patients treated for stage ib2/ii cervical carcinoma with chemoradiation therapy : Correlation of radiologic findings with surgicopathologic results. Cancer 113(8): 2158-2165, 2008. PMID: 18780318. DOI: $10.1002 / \mathrm{cncr} .23817$

11 Castelnau-Marchand P, Chargari C, Bouaita R, Dumas I, Farha G, Kamsu-Kom L, Rivin Del Campo E, Martinetti F, Morice P, Haie-Meder C and Mazeron R: What to expect from immediate salvage hysterectomy following concomitant chemoradiation and image-guided adaptive brachytherapy in locally advanced cervical cancer. Cancer Radiother 19(8): 710-717, 2015. PMID: 26508320. DOI: 10.1016/j.canrad.2015.05.025 
12 Touboul C, Uzan C, Mauguen A, Gouy S, Rey A, Pautier P, Lhomme C, Duvillard P, Haie-Meder C and Morice P: Prognostic factors and morbidities after completion surgery in patients undergoing initial chemoradiation therapy for locally advanced cervical cancer. Oncologist 15(4): 405-415, 2010. PMID: 3227965. DOI: 10.1634/theoncologist.2009-0295

13 Mazeron R, Gilmore J, Dumas I, Champoudry J, Goulart J, Vanneste B, Tailleur A, Morice P and Haie-Meder C: Adaptive $3 \mathrm{~d}$ image-guided brachytherapy: A strong argument in the debate on systematic radical hysterectomy for locally advanced cervical cancer. Oncologist 18(4): 415-422, 2013. PMID: 3639528. DOI: 10.1634/theoncologist.2012-0367

14 Haie-Meder C, Potter R, Van Limbergen E, Briot E, De Brabandere M, Dimopoulos J, Dumas I, Hellebust TP, Kirisits C, Lang S, Muschitz S, Nevinson J, Nulens A, Petrow P, Wachter-Gerstner $\mathrm{N}$ and Gynaecological GECEWG: Recommendations from gynaecological (GYN) GEC-ESTRO working group (i): Concepts and terms in 3D image based 3D treatment planning in cervix cancer brachytherapy with emphasis on mri assessment of GTV and CTV. Radiother Oncol 74(3): 235-245, 2005. PMID: 15763303. DOI: 10.1016/j.radonc.2004.12.015

15 Potter R, Haie-Meder C, Van Limbergen E, Barillot I, De Brabandere M, Dimopoulos J, Dumas I, Erickson B, Lang S, Nulens A, Petrow P, Rownd J, Kirisits C and Group GEW: Recommendations from gynaecological (GYN) GEC ESTRO working group (ii): Concepts and terms in 3D image-based treatment planning in cervix cancer brachytherapy-3d dose volume parameters and aspects of 3D image-based anatomy, radiation physics, radiobiology. Radiother Oncol 78(1): 67-77, 2006. PMID: 16403584. DOI: 10.1016/j.radonc.2005.11.014

16 Magne N, Chargari C, SanFilippo N, Messai T, Gerbaulet A and Haie-Meder C: Technical aspects and perspectives of the vaginal mold applicator for brachytherapy of gynecologic malignancies. Brachytherapy 9(3): 274-277, 2010. PMID: 20153985. DOI: 10.1016/j.brachy.2009.08.014

17 Gouy S, Morice P, Narducci F, Uzan C, Gilmore J, KolesnikovGauthier H, Querleu D, Haie-Meder C and Leblanc E: Nodalstaging surgery for locally advanced cervical cancer in the era of PET. Lancet Oncol 13(5): e212-220, 2012. PMID: 22554549. DOI: 10.1016/S1470-2045(12)70011-6

18 Haie-Meder C, Mazeron R and Magne N: Clinical evidence on pet-ct for radiation therapy planning in cervix and endometrial cancers. Radiother Oncol 96(3): 351-355, 2010. PMID: 22554549. DOI: $10.1016 /$ j.radonc.2010.07.010

19 Dindo D, Demartines N and Clavien PA: Classification of surgical complications: a new proposal with evaluation in a cohort of 6336 patients and results of a survey. Ann Surg 240(2): 205-213, 2004. PMID: 15273542. DOI: 10.1097/01.sla. 0000133083.54934.ae

20 Rijkmans EC, Nout RA, Rutten IH, Ketelaars M, Neelis KJ, Laman MS, Coen VL, Gaarenstroom KN, Kroep JR and Creutzberg CL: Improved survival of patients with cervical cancer treated with image-guided brachytherapy compared with conventional brachytherapy. Gynecol Oncol 135(2): 231-238, 2014. PMID: 25172763. DOI: 10.1016/j.ygyno.2014.08.027

21 Potter R, Georg P, Dimopoulos JC, Grimm M, Berger D, Nesvacil N, Georg D, Schmid MP, Reinthaller A, Sturdza A and Kirisits C: Clinical outcome of protocol based image (mri) guided adaptive brachytherapy combined with 3D conformal radiotherapy with or without chemotherapy in patients with locally advanced cervical cancer. Radiother Oncol 100(1): 116123, 2011. PMID: 3165100. DOI: 10.1016/j.radonc.2011.07.012

22 Colombo PE, Bertrand MM, Gutowski M, Mourregot A, Fabbro M, Saint-Aubert B, Quenet F, Gourgou S, Kerr C and Rouanet $\mathrm{P}$ : Total laparoscopic radical hysterectomy for locally advanced cervical carcinoma (stages iib, iia and bulky stages ib) after concurrent chemoradiation therapy: Surgical morbidity and oncological results. Gynecol Oncol 114(3): 404-409, 2009. PMID: 19555996. DOI: 10.1016/j.ygyno.2009.05.043

23 Lin LL, Yang Z, Mutic S, Miller TR and Grigsby PW: FDG-PET imaging for the assessment of physiologic volume response during radiotherapy in cervix cancer. Int $\mathrm{J}$ Radiat Oncol Biol Phys 65(1): 177-181, 2006. PMID: 16545921. DOI: 10.1016/ j.ijrobp.2005.12.016

24 McVeigh PZ, Syed AM, Milosevic M, Fyles A and Haider MA: Diffusion-weighted MRI in cervical cancer. Eur Radiol 18(5): 10581064, 2008. PMID: 18193428. DOI: 10.1007/s00330-007-0843-3

25 Fanfani F, Fagotti A, Gagliardi ML, Ferrandina G, Monterossi G, Gallotta V, Zannoni GF and Scambia G: Pre-hysterectomy cone biopsy is able to predict response in locally advanced cervical cancer patients submitted to neo-adjuvant chemoradiation. Eur J Surg Oncol 39(9): 1025-1029, 2013. PMID: 23827381. DOI: 10.1016/j.ejso.2013.06.003

26 Mazeron R, Gouy S, Chargari C, Rivin Del Campo E, Dumas I, Mervoyer A, Genestie C, Bentivegna E, Balleyguier C, Pautier $\mathrm{P}$, Morice $\mathrm{P}$ and Haie-Meder C: Post radiation hysterectomy in locally advanced cervical cancer: Outcomes and dosimetric impact. Radiother Oncol 120(3): 460-466, 2016. PMID: 27492204. DOI: 10.1016/j.radonc.2016.07.010

27 Duenas-Gonzalez A, Zarba JJ, Patel F, Alcedo JC, Beslija S, Casanova L, Pattaranutaporn P, Hameed S, Blair JM, Barraclough $\mathrm{H}$ and Orlando M: Phase III, open-label, randomized study comparing concurrent gemcitabine plus cisplatin and radiation followed by adjuvant gemcitabine and cisplatin versus concurrent cisplatin and radiation in patients with stage IIb to iva carcinoma of the cervix. J Clin Oncol 29(13): 1678-1685, 2011. PMID: 21444871. DOI: $10.1200 /$ JCO.2009.25.9663

28 Neoadjuvant Chemotherapy for Cervical Cancer Meta-Analysis Collaboration C: Neoadjuvant chemotherapy for locally advanced cervix cancer. Cochrane Database Syst Rev (2): CD001774, 2004. PMID: 15106161. DOI: 10.1002/146 51858.CD001774.pub2

29 Tewari KS, Sill MW, Long HJ, 3rd, Penson RT, Huang H, Ramondetta LM, Landrum LM, Oaknin A, Reid TJ, Leitao MM, Michael HE and Monk BJ: Improved survival with bevacizumab in advanced cervical cancer. N Engl J Med 370(8): 734-743, 2014. PMID: 4010094. DOI: 10.1056/NEJMoa1309748

30 Institute NC: Fda approval for bevacizumab. Available at: http:// wwwcancergov/cancertopics/druginfo/fda-bevacizumab, 2014.

31 Tewari KS, Sill MW, Monk BJ, Penson RT, Long HJ, 3rd, Poveda A, Landrum LM, Leitao MM, Brown J, Reid TJ, Michael HE and Moore DH: Prospective validation of pooled prognostic factors in women with advanced cervical cancer treated with chemotherapy with/without bevacizumab: $\mathrm{Nrg}$ oncology/gog study. Clin Cancer Res 21(24): 5480-5487, 2015. PMID: 4896296. DOI: 10.1158/1078-0432.CCR-15-1346

Received April 19, 2019

Revised May 21, 2019

Accepted May 24, 2019 